\title{
Associated Factors to Nutritional Status and Infant and Young Child Feeding (IYCF) Practices in Rural Area of Burkina Faso: A Study in Ouargaye Health District
}

\author{
Siri Baperman Abdel Aziz ${ }^{1}$, Bengaly Marcel $^{2}$, Konkonbo/Kouanda Zenab ${ }^{3}$, Coulibaly Soumaila ${ }^{1}$, \\ Garanet Franck ${ }^{4}$, Catraye Dossou Joseph ${ }^{5}$ \\ ${ }^{1}$ Minsitry of Health, Ouagadougou, Burkina Faso \\ ${ }^{2}$ Department of Life and Earth Sciences, University of Ouaga I Pr Joseph Ki-Zerbo, Ouagadougou, Burkina Faso \\ ${ }^{3}$ World Bank, Ouagadougou, Burkina Faso \\ ${ }^{4}$ Institute of Research in Health Sciences, Ouagadougou, Burkina Faso \\ ${ }^{5}$ Private Department of Public Health Support, Ouagadougou, Burkina Faso
}

Email address:

siribf@yahoo.fr (S. B. A. Aziz)

\section{To cite this article:}

Siri Baperman Abdel Aziz, Bengaly Marcel, Konkonbo/Kouanda Zenab, Coulibaly Soumaila, Garanet Franck, Catraye Dossou Joseph. Associated Factors to Nutritional Status and Infant and Young Child Feeding (IYCF) Practices in Rural Area of Burkina Faso: A Study in Ouargaye Health District. American Journal of Pediatrics. Vol. 5, No. 3, 2019, pp. 82-90. doi: 10.11648/j.ajp.20190503.12

Received: April 18, 2019; Accepted: June 14, 2019; Published: July 1, 2019

\begin{abstract}
Although the global trend of malnutrition among children under five is declining, it remains a major public health problem in developing countries such as Burkina Faso. IYCF are major determinants of nutritional status and hence health and child survival. Material and Method: We carried out a cross-sectional study in primary health care centers randomly selected. The objectives of this work were to analyze associated factors to children's nutritional status and child feeding. The Z-scores (WHO, 2006) were used to determine nutritional's status of the children. The quality of feeding practices was assessed according to IYCF index. Results: In total, we surveyed 287 children. The average age of children was 10.87 months. The sex ratio was at 1:11. Among children, the prevalence of underweight was $19.2 \%$, that of stunting $31.2 \%$ and that of wasting $10.1 \%$. Multigravidity was the predictive risk factor related to underweight in children. Practice of EBF was associated with Zscore Height/Age $(\mathrm{p}=0.04)$. The majority $(70 \%)$ of children had a good score of IYCF index. Among children aged 9-12 months, the Z-score Height/Age $(p=0.04)$ and $\mathrm{Z}$-score Weight/Height $(\mathrm{p}=0.001)$ were associated with IYCF index in univariate analysis. For those with at least 12 months of age, sex ant type of habit was the predictive risk factors associated to IYCF index. Conclusion: Malnutrition is common in children. Feeding practices are good and are not associated with sociodemographic characteristics of mothers. IYCF index score decreases with age and is lower after 12 months.
\end{abstract}

Keywords: Child, Nutritional Status, Infant and Young Child Feeding (IYCF)

\section{Background}

According to World Health Organization (WHO) and United Nations Children's Fund (UNICEF), the global trend child in the prevalence of child malnutrition is declining between 1990 and 2014 with however regional inequalities in this world progress. Malnutrition in children continues to be a major public health problem in many developing countries [1]. In Burkina Faso, according to the 2015 national nutrition survey, the prevalence of underweight, chronic malnutrition and acute malnutrition were respectively $23 \%, 30.2 \%$ and
$10.4 \%$ [2].

Optimal newborn, infants and young children feeding determines its nutritional and health, as much current, and future. Inadequate feeding practices, such as those related to early breastfeeding, exclusive breastfeeding, withdrawal, and complementary feeding are the causes of many nutritional and health problems in children. Malnutrition is a major underlying cause of infant and child morbidity and mortality. Optimal breastfeeding up to the age of two years could prevent 823,000 deaths each year [3].

Breastfeeding would have beneficial adverse effects on 
certain non-communicable diseases including hypertension, obesity, hypercholesterolemia [4-6] and diabetes [3]. In addition, breastfeeding is associated with better social development and cognitive development of the child [7]. Failure to breastfeed may be a consequence of unequal access to care and maybe both a cause and a consequence of social inequality [8]. For nursing mothers, breastfeeding reduces the risk of breast and ovarian cancer [6]. Feeding practices in infants may be influenced by cultural factors [9-10], racial [11], environmental and economic [12] but also mothers sociodemographic such as age [13], education levels [14], parity, occupational status or psychological profile [15]. In low-income and middle-income countries, only $37 \%$ of children younger than 6 months of age are exclusively breastfed [3]. The Burkina Faso 2010 Demographic and Health Survey reported that only $25 \%$ of children under six months of age were exclusively breastfed and $3 \%$ of children aged 6-23 months were fed appropriately on the basis of food diversity [16]. The true measure of the quality of children feeding is difficult to reach nevertheless some approaches have been proposed through the analysis of a score [16]. Also, the relationship of this score with the nutritional status is complex to establish because of the multiple factors that influence this one. Adequate nutrition for infants and young children contributes directly and indirectly to the achievement of sustainable development goals. Although it is an obvious strategy to promote health and improve survival [18], practices are not always appropriate [19]. This study analysed factors associated with the nutritional status and infant and young child feeding practices in the context of the health district of Ouargaye.

\section{Methodology}

\subsection{Site, Design, Sampling and Data Collection}

This cross-sectional study carried out in twenty-nine (29) primary health-care facilities in Ouargaye's District included 287 couple mother-child from July to September 2015. The detail on study site, design, sample size, and data collection were already described elsewhere [20].

\subsubsection{Anthropometric Measure in Children}

a) The weight was measured using a scale type SECA in children over two years of age and a Salter type scale with a maximum capacity of $25 \mathrm{~kg}$ in children under two years of age, cleared of their clothing. The scale was calibrated nearest $100 \mathrm{~g}$. The scales were weighed each series of weighing to avoid errors.

b) Child's height was measured using a vertical gage in children aged two years or more. The length was taken horizontally in children who do not yet walk by making sure that the heels, buttocks, back, and neck are in contact with the support, the gaze of the child-directed in the perpendicular plane to the support. The height value was read to within $0.1 \mathrm{~cm}$.

\subsubsection{Anthropometric Measure in Mothers}

a) Mother's weight was measured using a Seca weighing scale with an accuracy of $0.1 \mathrm{Kg}$ and standing height by a measuring rod with a precision of 10 centimeters.

b) Abdominal perimeter is correlated with the amount of visceral adipose tissue. The abdominal perimeter of mothers was measured with a tape measure, the subject standing and gently exhaling. The tape measure was placed around the waist midway between the last floating sides and the upper edges of the iliac crests.

\subsubsection{Infant and Young Child Feeding (IYCF) Practices}

Mothers were interviewed about the infant and child feeding practices, such as breastfeeding during the past twenty-four 24 hours (if the mother is breastfeeding, do the child has been breastfed the last 24 hours: yes/no?), bottle feeding (does baby bottles have been used to feed the child during the past 24 hours: yes/no?), dietary diversity related to the number of food group consumed during the past 24 hours (whether or not the child received selected food groups in the previous 24 hours?), food group frequency during the last seven days' (how many days in the last seven days did the child eat the selected food groups?) and meal frequency during the last 24 hours preceding the survey (how many times during the last 24 hours did the child eat solid or semisolid food, including snack and meal?). Food groups are Grains \& tubers, leguminous \& nut, milk, fish/poultry \& meat, eggs, fruit \& vegetable rich in vitamin A, other fruits \& vegetables.

\subsection{Categorization and Data Analysis}

Data were entered using Epi data 3.1 and analyzed with SPSS software (version 21).

a) Length/Height-for-age, weight-for-age, and weight-forheight categories were generated for children under five based on the World Health Organization growth standards (WHO, 2006), whereby stunting (low heightfor-age), underweight (low weight-for-age), and wasting (low weight-for-height) are defined as z-scores of $<-2$ standard deviations.

b) Mother's Body Mass Index (BMI) was calculated as weight in kilograms divided by height in meter squared. Cut-off points of $<18.50,18.5-24,99,25.00-29.99$, and $\geq 30 \mathrm{~kg} / \mathrm{m}^{2}$ was used respectively for underweight, normal, overweight and obesity.

c) Mother's Waist circumference was used as measures of abdominal obesity, defined as a waist circumference> $88 \mathrm{~cm}$.

IYCF score was created as described by Menon and Ruel at the difference that for dietary diversity we considered Meat/fish/poultry and egg instead of fish/poultry/egg and meat in Ruel's study [17]. Five variables were used to create the IYCF score as shown in table 1. The final child feeding index was a summation of the scores obtained for each variable described above. The index ranged from 0 to 12 for all three age groups. Within each age group, the child feeding index scores were grouped into two categories of feeding 
practices: low and average (weak) when the sum of scores obtained is $\leq 6$ points and high (good) when it's $>6$ points.
The constitution of this score takes into account the recommendations regarding infants and young feeding.

Table 1. Variables and scoring system used to create infant and child feeding index for children by age group.

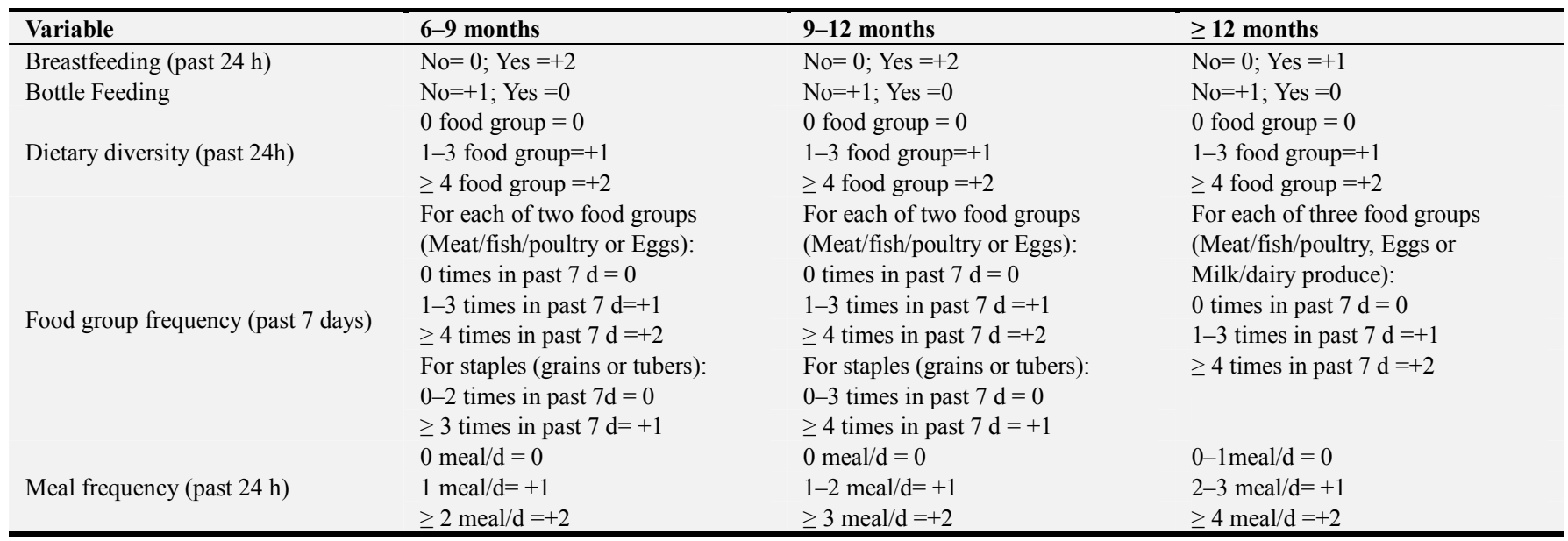

$\mathrm{d}=$ day. Adapted from Ruel and Menon (2)

\subsection{Statistical Analysis}

Between independent variables and child nutritional status as well as IYCF index was determined using Chi-square test and $\mathrm{p}$-value $<0.05$ was considered statistically significant. The explicative variables associated with the dependents with a threshold of $\mathrm{p}<0.2$ were included in the multivariate analysis by logistic regression.

\section{Results}

\subsection{Socio-Demographic Characteristics}

Between July $25^{\text {th }}$ to September $7^{\text {th }} 2015,287$ couple mothers-child were included in this study. The mean age of the children was 10.87 months with a standard deviation of \pm 4.18 . The age ranged from 6 to 31.9 months with a median of 9.5. The sex ratio was at $1: 11$. Sociodemographic characteristic of mothers and households have been described in a previous study [20]. The proportions of undernutrition (BMI $<18.5 \mathrm{Kg} / \mathrm{m}^{2}$ ) and excess weight $\left(\mathrm{BMI}>25 \mathrm{Kg} / \mathrm{m}^{2}\right)$ in mothers were 16.3 and 10.5 , respectively.

\subsection{Nutritional Status and Associated Factors Among Child}

\subsubsection{Birth's Weight}

Children's mean birth weight was 2947.79 grams with a standard deviation of \pm 462 and extremes of 1700 and 4200 grams. The proportion of low birth weight was $12.61 \%$.

\subsubsection{Current Nutritional Status}

Among children, results showed 19.2\% of underweight, $31.4 \%$ of stunting and $11.1 \%$ of was wasting (table 2 ).

Table 2. Prevalence of the type of malnutrition by age group.

\begin{tabular}{lllll}
\hline Age (months) & n & \% of WAZ $<-2$ & \% of HAZ $<-2$ & $\%$ of $\mathbf{W H Z}<-2$ \\
\hline $6-9$ & 108 & 11.1 & 16.7 & 13 \\
$9-12$ & 92 & 14.1 & 27.2 & 12 \\
12 and + & 87 & 34.5 & 54 & 8 \\
Total & 287 & 19.2 & 31.4 & 11.1 \\
\hline
\end{tabular}

In univariate analysis, nutritional status did not differ significantly by gender. Number of pregnancies was statistically associated with WAZ score $(p=0.029)$. Habitat's type $(p=0.006)$, mother's BMI $(p=0.038)$ and level of knowledge about benefits of breastfeeding $(\mathrm{p}=0.02)$ were statistically associated with HAZ score (table 3 ).

Table 3. Associated factors with child nutritional status in univariate analysis.

\begin{tabular}{|c|c|c|c|c|c|c|c|c|c|c|c|c|}
\hline \multirow{2}{*}{ Variable } & \multicolumn{4}{|c|}{ WAZ <-2 (Underweight) } & \multicolumn{4}{|c|}{ HAZ <-2 (Stunting) } & \multicolumn{4}{|c|}{ WHZ <-2 (Wasting) } \\
\hline & $\mathbf{n}$ & $\%$ & OR,95\% CI & $\mathbf{p}$ & $\mathbf{n}$ & $\%$ & OR,95\% CI & $\mathbf{p}$ & $\mathbf{n}$ & $\%$ & OR,95\% CI & $\mathbf{p}$ \\
\hline Child's Sex & & & & 0.56 & & & & 0.353 & & & & 0.95 \\
\hline Male & 151 & 17.9 & $0.84(0.46-1.50)$ & & 151 & 33.8 & $1.46(0.80-2.80)$ & & 151 & 11.3 & $1.02(0.49-2.13)$ & \\
\hline Female & 136 & 20.6 & 1 & & 136 & 28.7 & 1 & & 136 & 11 & 1 & \\
\hline Birth's weight (g) & & & & 0.15 & & & & 0.127 & & & & 0.91 \\
\hline$<2500$ & 27 & 29.6 & $1.94(0.78-4.8)$ & & 26 & 42.3 & $1.88(0.82-4.27)$ & & 27 & 11.1 & $1.06(0.29-3.86)$ & \\
\hline$\geq 2500$ & 191 & 17.8 & 1 & & 190 & 29.5 & 1 & & 191 & 10.5 & 1 & \\
\hline$<25$ & 124 & 16.1 & $0: 52(0.22-1.21)$ & & 123 & 26.8 & $0.5(0.21-1.19)$ & & 124 & 11.3 & $1.17(0.36-3.8)$ & \\
\hline$[25-35[$ & 114 & 21.1 & $0.66(0.29-1.52)$ & & 114 & 33.3 & $0.84(0.36-1.96)$ & & 114 & 11.5 & $1.19(0.37-3.87)$ & \\
\hline$\geq 35$ & 41 & 26.8 & 1 & & 40 & 40 & 1 & & 41 & 9.8 & 1 & \\
\hline Mother Education level & & & & 0.136 & & & & 0.05 & & & & 0.635 \\
\hline
\end{tabular}




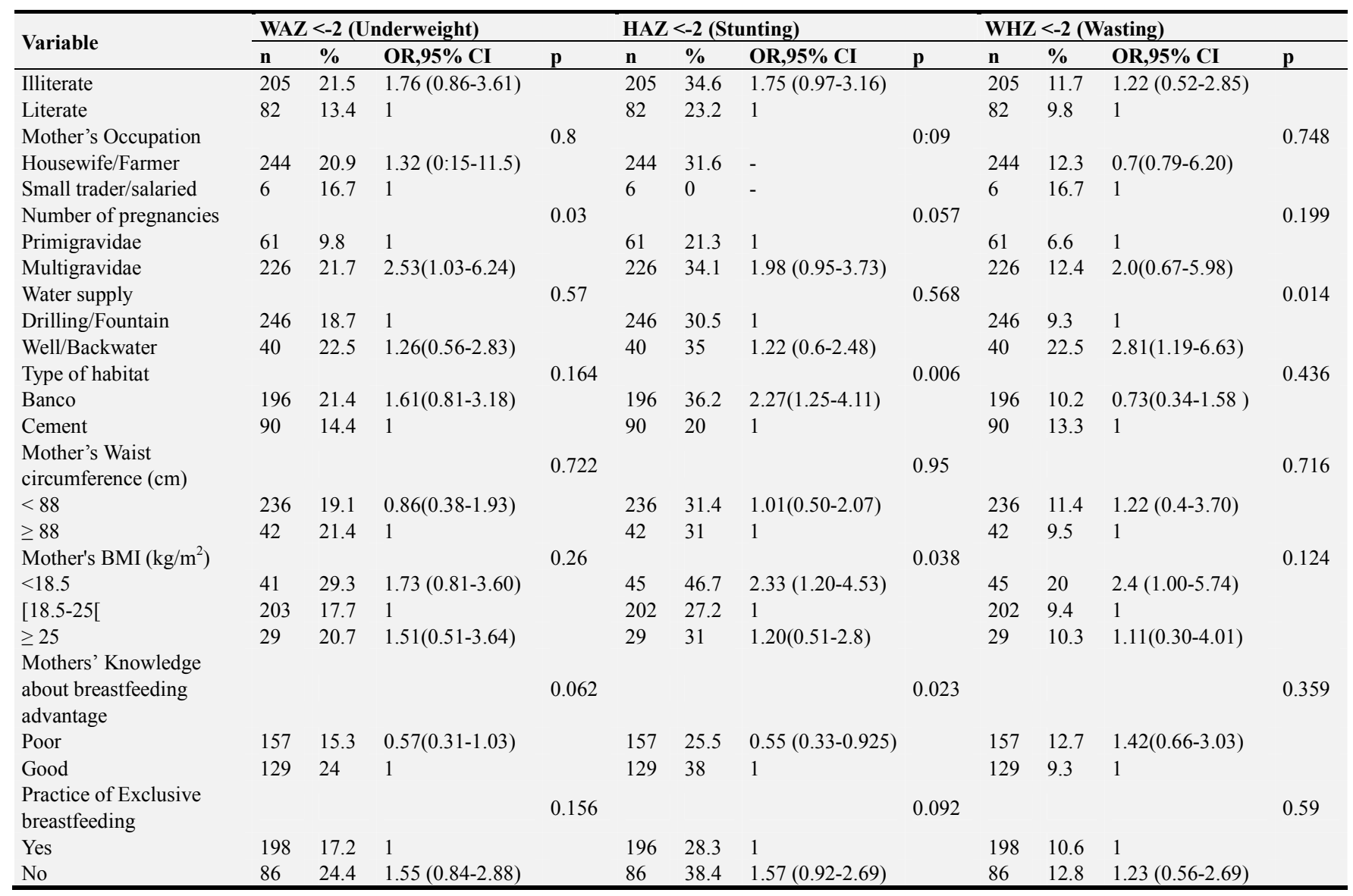

$\mathrm{OR}=$ Odd Ratio

In multivariate analysis, multigravidity $(\mathrm{AOR}=2.95 ; 95 \% \mathrm{CI}: 1.02-8.41)$ was the predictive risk factor related to underweight in children (table 4). Among children, those whose mothers were multigravidae had three times more likely to be in underweight. No independent variables were statistically associated with stunting or wasting.

Table 4. Associated factors to child nutritional status in multivariate analysis.

\begin{tabular}{lllllll}
\hline \multirow{2}{*}{ Independent variable } & WAZ & & HAZ & WHZ & p \\
\cline { 2 - 6 } & AOR & p & AOR & p & AOR & - \\
\hline $\begin{array}{l}\text { Number of pregnancies } \\
\text { Primigravidae }\end{array}$ & 1 & 0.029 & - & - & \\
Multigravidae & $2.95(1.02-8.41)$ & & & & \\
\hline
\end{tabular}

AOR=Adjusted Odd Ratio

\subsection{IYCF Index and Associated Factors}

It was noted that the breastfeeding practice was very frequent (99\%) and bottle use was not adopted by mothers. IYCF index scores were satisfactory. About four out of five children (79.1\%) had a good IYCF index. Respectively, 84.25\%, 78.40\% and $73.3 \%$ of children aged 6-9, 9-12 and over 12 months had a good IYCF score (table 5).

Table 5. Indicators of components of IYCF index by age groups.

\begin{tabular}{|c|c|c|c|}
\hline Age & 6-9 months $n=108$ & 9-12 months $n=89$ & 12 months and $+n=86$ \\
\hline Breastfeeding ( past 24 hours) & Yes $=99 \%$ & Yes $=100 \%$ & Yes $=98.8 \%$ \\
\hline Bottle feeding & $\mathrm{No}=100 \%$ & No $=100 \%$ & No $=100 \%$ \\
\hline Food diversity & $\begin{array}{l}0 \text { group: } 10.2 \% \\
1-3 \text { groups: } 41.7 \% \\
\geq 4 \text { groups: } 48.1 \%\end{array}$ & $\begin{array}{l}0 \text { group: } 3.4 \% \\
1-3 \text { groups: } 59.6 \% \\
\geq 4 \text { groups: } 37.1 \%\end{array}$ & $\begin{array}{l}0 \text { group: } 2.3 \% \\
1-3 \text { groups: } 33.7 \% \\
\geq 4 \text { groups: } 64 \%\end{array}$ \\
\hline Frequency of consumption (score) & $\begin{array}{l}\text { Score }<60 \%: 44.44 \% \\
M d=0.6 \pm 0.31\end{array}$ & $\begin{array}{l}\text { Score }<60 \%: 44.9 \% \\
\mathrm{Md}=0.6 \pm 0.31\end{array}$ & $\begin{array}{l}\text { Score }<60 \%: 53.5 \% \\
M d=0.5 \pm 0.29\end{array}$ \\
\hline Number of meal & $\begin{array}{l}0 \text { time: } 8.3 \% \\
1-2 \text { time: } 0.9 \%\end{array}$ & $\begin{array}{l}0 \text { time: } 3.4 \% \\
1-2 \text { time: } 19.1 \%\end{array}$ & $\begin{array}{l}0-1 \text { times: } 5.8 \% \\
2-3 \text { times: } 53.5 \%\end{array}$ \\
\hline
\end{tabular}




\begin{tabular}{llll}
\hline Age & $\mathbf{6 - 9}$ months $\mathbf{n}=\mathbf{1 0 8}$ & $\mathbf{9 - 1 2}$ months $\mathbf{n}=\mathbf{8 9}$ & $\mathbf{1 2}$ months and + $\mathbf{n}=\mathbf{8 6}$ \\
\hline & $\geq 3$ times: $90.7 \%$ & $\geq 3$ times: $77.5 \%$ & $\geq 4$ times: 40.7 \\
Mean, SD & $2.93 \pm 1.26$ & $3 \pm 1.17$ & $3.49 \pm 1.46$ \\
IYCF Index & & & \\
Mean, SD & $8.65 \pm 2.48$ & $8.54 \pm 2.3$ & $7.99 \pm 2.34$ \\
Range & {$[3-12]$} & {$[3-12]$} & {$[3-12]$} \\
Proportion of children with a good score of IYCF index & $84.25 \%$ & $78.40 \%$ & $73.3 \%$ \\
\hline
\end{tabular}

$\mathrm{SD}=$ Standard deviation.

The proportion of children with a good IYCF index decreases with age (table 5), however, in univariate analysis, IYCF index mean did not differ statistically according to children's age $(\mathrm{p}=0.136)$ as shown in table 6 . We found a significant statistical relation between gender and IYCF score $(\mathrm{p}=0.008)$ but this association was only significant in 12 months and over age's group ( $\mathrm{p}=0.015)$ as levels of mother's knowledge about advantage of breastfeeding $(\mathrm{p}=0.04)$ and type of habitat $(\mathrm{p}=0.001)$.

For 9-12 months' old children, IYCF index was statistically associated with $\mathrm{HAZ}(\mathrm{p}=0.04)$ and WHZ $(\mathrm{p}=0.00)$ scores. In this age group, the children with a good nutritional status about HAZ and WAZ scores seem to have a higher IYCF index score as shown in the table 5 below. Otherwise, mother's BMI was associated with IYCF index $(\mathrm{p}=0.02)$ in this age group.

Table 6. Associated Factors to IYCF index in univariate analysis.

\begin{tabular}{|c|c|c|c|c|c|c|c|c|c|}
\hline \multirow{2}{*}{ Variables } & \multicolumn{3}{|c|}{ 6-9 months } & \multicolumn{3}{|c|}{ 9-12 months } & \multicolumn{3}{|c|}{12 month and +} \\
\hline & $\mathbf{n}$ & Good IYCFI (\%) & $\mathbf{p}$ & $\mathbf{n}$ & Good IYCFI (\%) & $\mathbf{p}$ & $\mathbf{n}$ & Good IYCFI (\%) & $\mathbf{p}$ \\
\hline Sex & & & 0.283 & & & 0.283 & & & 0.015 \\
\hline Male & 57 & 80.7 & & 46 & 73.2 & & 28 & 62.2 & \\
\hline Female & 51 & 88.2 & & 42 & 83.3 & & 35 & 85.4 & \\
\hline Mother's age (years) & & & 0.13 & & & 0.22 & & & 0.15 \\
\hline$<25$ & 58 & 82.8 & & 41 & 70.7 & & 24 & 62.5 & \\
\hline $25-34$ & 32 & 93.8 & & 38 & 86.8 & & 41 & 78 & \\
\hline Mother's education level & & & 0.57 & & & 0.46 & & & 0.08 \\
\hline Illiterate & 72 & 86.1 & & 66 & 80.3 & & 64 & 78.1 & \\
\hline Literate & 36 & 80.6 & & 22 & 72.7 & & 22 & 59.1 & \\
\hline Number of pregnancies & & & 0.21 & & & 0.37 & & & 0.75 \\
\hline Primigravidae & 31 & 87.1 & & 21 & 71.4 & & 9 & 77.8 & \\
\hline Multigravidae & 77 & 83.1 & & 67 & 80.6 & & 77 & 72.7 & \\
\hline Water supply & & & 0.77 & & & 0.1 & & & 0.14 \\
\hline Type of habitat & & & 0.06 & & & 0.83 & & & $0.001 *$ \\
\hline Banco & 67 & 79.1 & & 62 & 79 & & 64 & 82.8 & \\
\hline Cement & 41 & 92.7 & & 26 & 76.9 & & 22 & 45.5 & \\
\hline Mother's BMI $\left(\mathrm{Kg} / \mathrm{m}^{2}\right)$ & & & 0.669 & & & $0.02 *$ & & & 0.55 \\
\hline$<18.5$ & 17 & 88.2 & & 7 & 71.4 & & 17 & 70.6 & \\
\hline$[18.5-25[$ & 77 & 85.7 & & 68 & 85.3 & & 54 & 70.4 & \\
\hline$\geq 25$ & 8 & 75 & & 7 & 42.9 & & 14 & 85.7 & \\
\hline $\begin{array}{l}\text { Mother's Knowledge about } \\
\text { advantage of breastfeeding }\end{array}$ & & & 0.589 & & & 0.06 & & & $0.04 *$ \\
\hline Poor & 70 & 85.7 & & 49 & 85.7 & & 37 & 62.2 & \\
\hline Good & 38 & 81.6 & & 39 & 69.2 & & 49 & 81.6 & \\
\hline Practice of EBF & & & 0.806 & & & 1 & & & 0.37 \\
\hline Yes & 80 & 83.8 & & 55 & 78.2 & & 61 & 70.5 & \\
\hline No & 28 & 85.7 & & 32 & 78.1 & & 25 & 80 & \\
\hline Anthropometric variable & & & & & & & & & \\
\hline$\geq-2$ & 90 & 85.6 & & 63 & 84.1 & & 40 & 75 & \\
\hline WAZ & & & 0.926 & & & 0.1 & & & 0.705 \\
\hline$<-2$ & 12 & 83.3 & & 11 & 36.4 & & 6 & 66.7 & \\
\hline$\geq-2$ & 96 & 84.4 & & 77 & 84.4 & & 80 & 73.8 & \\
\hline WHZ & & & 0.926 & & & $0.000 *$ & & & 0.99 \\
\hline$<-2$ & 12 & 83.3 & & 13 & 61.5 & & 30 & 73.3 & \\
\hline$\geq-2$ & 96 & 84.4 & & 75 & 81.3 & & 56 & 73.2 & \\
\hline
\end{tabular}

In multivariate analysis, mother's BMI was the only predictive risk factor associated to IYCFI among children of 9-12 months of age. For those with at least 12 months of age, sex ant type of habit was the predictive risk factors associated to IYCF index as shown in the table 7. 
Table 7. Associated factors to IYCF index in multivariate analysis by logistic regression.

\begin{tabular}{|c|c|c|c|c|c|c|}
\hline \multirow{3}{*}{ Independent's variable } & \multicolumn{2}{|l|}{ 6-9 months } & \multicolumn{2}{|l|}{ 9-12 months } & \multicolumn{2}{|l|}{12 month and +} \\
\hline & Good IYCFI & & Good IYCFI & & Good IYCFI & \\
\hline & AOR 95\% IC & p-value & AOR 95\% IC & p-value & AOR 95\% IC & p-value \\
\hline Sex & - & & - & & & \\
\hline Male & & & & & 1 & \\
\hline Female & & & & & $3.67(1.07-12.51)$ & $0.037^{*}$ \\
\hline Type of habitat & - & & - & & & \\
\hline Banco & & & & & $0.18(0.05-0.642)$ & $0.008^{*}$ \\
\hline Mother's BMI & - & & - & & - & \\
\hline$<18.5$ & & & $0.08(0.00-0.95)$ & 0.046 & & \\
\hline$[18.5-25[$ & & & $0.16(0.10-2.63)$ & 0.20 & & \\
\hline$\geq 25$ & & & 1 & & & \\
\hline
\end{tabular}

\section{Discussion}

This paper describes the nutritional status, IYCF practices, and associated factors in a rural area of Burkina Faso. The present study showed that malnutrition, particularly wasting and stunting were widespread. Prevalence of underweight and stunting increase with age. The number of pregnancies who had had the mother was associated with child WAZ score. We noted that the IYCF index was satisfactory and decreased with age, although this association was not statistically significant.

\subsection{Birth Weight}

Our study shows that $12,61 \%$ of children were born with low birth weight. This proportion is similar to that reported (14\%) by the literature in low-income countries [21]. Low birth weight may constitute a risk factor of childhood illness, mortality [22] and non-communicable disease (NCDs) such as diabetes and heart disease later in life [23].

\subsection{Current Child Nutritional Status}

Prevalence of stunting and wasting were high, respectively $31.2 \%$ and $10.1 \%$. These values are similar to those found at the national level during the 2015 nutrition survey [23] and are above the critical thresholds according to WHO classification for assessing the severity of malnutrition by prevalence ranges among children under five years of age. The country experienced a food crisis in 2012 and the health system is still struggling to detect and maintain the cases of malnutrition in the medical and nutritional care cohorts. Also, food security interventions need to be effective and sustainable to support health promotion malnutrition's care activities.

\subsection{Associated Factors to Nutritional Status}

In contrast to evidence about the positive relationship between the mother's education level and the nutritional status of the child, we found no statistical association for WAZ, HAZ, and WHZ. This could be due to the effect of "unobserved factors" that may influence both the mother's education and child nutritional status. Also, some study has shown that the level of the mother should be sufficiently high (at least 9-13 years of schooling) to positively and statistically influence the nutritional status of the child [2425]. Lower levels of maternal education do not have a significant impact in reducing child malnutrition. In our study, the proportion of mothers with a post-primary level $(8 \%)$ was very low. This suggests the need to keep girls in school a long time enough to discount the benefits of their education on the nutritional status and health of their children.

In our study, the number of pregnancies was statistically associated WAZ score $(\mathrm{p}=0.029)$ in multivariate analysis. A similar association has been described [26]. The children whose mothers were multigravidae had three times more likely to be in underweight. The number of pregnancies can be a proxy for the number of children in the household, his size, and economic level. Thus, the fact that the mother is multigravidae could result in a larger size of the household and less access to food and care for children compared to primigravidae, which would expose them to greater vulnerability to underweight. In Burkina Faso, the fertility rate in 2015 was at 5.4 .

In univariate analysis, mother's BMI was associated with child HAZ score $(\mathrm{p}=0.038)$. The children whose mothers were in undernutrition had two times more likely to be stunted. Stunting in children reflects chronic malnutrition and low maternal body-mass index is associated with intrauterine growth restriction [27]. The association we found could be due to a precarious nutritional status of the mother during the preconception period or pregnancy that would favor a nonoptimal nutritional status of the child. Nearly four women out of five (16.4\%) in our study were underweight. This involves preventing malnutrition and promoting the nutrition of the girl and the mother during the prenatal and postnatal period. Several other studies have found associations between maternal undernutrition and stunting in children [28-30]. The relationship is well established between the small size of the mother and stunting in children [31].

\subsection{Infant and Young Children Feeding Score and Associated Factors}

In our study, nearly four in five children (79\%) had a good score of IYCF index which is satisfactory. This could be partly explained by the fact that almost all mothers in our study were no professional occupation and therefore have 
more time to breastfeed their children. The majority (99\%) of them still breastfeed at the time of the study, which compensates somewhat nutritional needs of their children. Although the nutritional quality of breast milk decreases after six months and food supplementation may be inappropriate.

In the present study, respectively $84.25 \%, 78.4 \%$ and $60.57 \%$ of children aged 6-9 months, 9-12 months and 12 months or more had a good IYCF index score. Our results are different from those of Sawadogo study in Burkina [10], which reported a lower proportion of good IYCF index among children in a rural area of Burkina selected in households. This difference could be explained by contextual factors. In Sawadogo's study, only $94.8 \%$ and $34.8 \%$ of children aged 12-23 months and 24-36 months were breastfed by cons, in our study, $99 \%$ of children were breastfed. When children are breastfed they have more contact with their mothers and more chance of being better fed. Also, our population was selected in health facilities during healthy infant care. In the context of Burkina Faso, where coverage of healthy infant care is very low, the strategy concerns the age group of $0-5$ years old with a calendar of visits: 1 visit / month in the first year; 1visite / 2 months at the course of the second year and 1 visit $/ 3$ months until the old age. This monitoring also aims to: (i) advise on the continuation of EBF for up to six months; (ii) Advise on continued breastfeeding for up to two years; (iii) Advise mothers and families about complementary feeding practices, and (iv) micronutrient supplementation.

\subsection{IYCF Index and Anthropometric Parameters}

In univariate analysis, mothers with a normal BMI were more likely to have children with a good score of IYCF index in the age's groups 9-12 months $(\mathrm{p}=0.02)$. We did not find any association between sociodemographic characteristics of mothers and ICYF index's score. By cons, Ruel noted that some sociodemographic characteristics of mothers as ethnicity (Guatemala), socioeconomic level of the household (Nicaragua and Colombia) and the level of education (Peru) conditioned associations between feeding practices and the $\mathrm{Z}$ Score Height/Age [17]. In our study, the IYCF score was statistically associated with Z-score Height/Age $(\mathrm{p}=0.04)$ and Weight/Height $(p=0.00)$ in the age group of $9-12$ months. This result suggests improving feeding practices at this age group in our context. Our results are similar to those of Bork in Senegal, which has shown a strong association between the IYCF score and the $Z$ score Height/Age in children aged 6-12 months [32]. Sawadogo has also documented similar results by finding associations between IYCF index and Z score Weight/Height in children aged 6-11 months and with $Z$ score Height/Age in 6-23 months [10]. By cons, Zhang in a study in rural China community among children aged 6-11 months had observed no association between the Z Score Height/Age and the Z score IYCF index but he noted, however, an association between the $Z$ Score Weight/Age and the IYCF score [33].

We noted that the prevalence of underweight and stunting increases with age to be higher in children 12 months and older. The frequency of infections, higher after the age of 12 months and inappropriate feeding practices could explain this trend. Furthermore, we noted in our study that the food index score decreased with age.

\section{Conclusion}

The current study showed that malnutrition in all its forms is common among children in healthy infant care. By cons, a strong point of best feeding practices is the continuation of breastfeeding and the no bottle feeding. Multigravidity is a risk factor of underweight in children. The rural context of our study, less exposed to advertisements on breast milk substitutes, lack of employment of mothers and their weak financial ability to procure bottle milk seems to have encouraged the large practice of breastfeeding. The feeding practices evaluated through the IYCF index is globally satisfactory. However, this index score decreases with age and is lower after 12 months. Feeding practices were not associated with sociodemographic characteristics of mothers. There is a need to further explore the factors influencing complementary feeding. Local sustainable food security strategies coupled with communication activities for social and behavioral change in favor of child nutrition will undoubtedly lead to further improvements in feeding practices especially after 12 months and so improve the nutritional status of children.

\section{List of Abbreviations}

EBF: Exclusive Breastfeeding IYCFI: Infant and Young Child Feeding Index. WHO: World Health Organization. UNICEF: United Nations Children's Fund

Declarations

a) Ethics approval and consent to participate

Our study required the approval of the local committee.

Maternal consent was requested prior to the investigation.

Questionnaires and data did not identify the respondents.

b) Consent for publication

Not applicable

c) Availability of data and material

Please contact the author for data requests

d) Competing interests

The authors declare that there is no conflict of interests regarding the publication of this paper.

e) Funding

No fund was provided for this research

\section{Limit}

The limitations of this study is partly related to recall errors, memory bias, lack of quantitative measures of food, and also the fact that feeding practices are dynamic over time.

\section{Authors' Contributions}

Baperman Siri developed the concept, participated in data 
collection and analysis, and wrote the paper. Marcel Bengaly, Joseph Catraye and Zenab Kouanda contributed in data analysis and critically reviewed of the paper. Soumaila Coulibaly, Franck Garanet and Evrard Sorgho participated in data analysis. All the authors read and approved the final paper.

\section{Acknowledgements}

We thank the mothers who participated in this study for their cooperation and patience. We thank the health promotion facilitators of the NGO Medicus Mundi and the nurses of the health district of Ouargaye who helped with the data collection.

\section{References}

[1] UNICEF, WHO and World Bank Group. Levels and trends in child malnutrition. Key findings of the 2015 edition. 2015. [Cited 13 July 2013]. Available from: https://data.unicef.org/resources/levels-and-trends-in-childmalnutrition-2015-edition/jme-2015-edition-sept-2015_203$3 /$.

[2] Ministère de la Santé., 2015. Rapport de l'Enquête nutritionnelle nationale 2015 du Burkina Faso.

[3] Victora CG, Bahl R, Barros AJD, França GVA, Horton S, Krasevec J, et al. Breastfeeding in the 21 st century: epidemiology, mechanisms, and lifelong effect. The Lancet. Janv 2016; 387 (10,017):475-90.

[4] Roya Kelishadi and Sanam Farajian. The protective effects of breastfeeding on chronic non-communicable diseases in adulthood: A review of evidence. Adv Biomed Res. 2014; 3:3.

[5] Davis MK. Breastfeeding and chronic disease in childhood and adolescence. Pediatr Clin North Am. 2011; 48:125-41.

[6] Ip S, Chung M, Raman G, Chew P, Magula N, DeVine D, Trikalinos T, Lau J. Breastfeeding and Maternal and Infant Health Outcomes in Developed Countries. Evidence Report/Technology Assessment No. 153 (Prepared by TuftsNew England Medical Center Evidence-based Practice Center, under Contract No. 290-02-0022). AHRQ Publication No. 07E007. Rockville, MD: Agency for Healthcare Research and Quality. April 2007.

[7] Quigley AM, Hockley C, Carson C, Kelly Y, Renfrew MJ, Sacker A. Breastfeeding is Associated with Improved Child Cognitive Development: A Population-Based Cohort Study. J Pediatr 2012; 160:25-32.

[8] Renfrew, M. J., Pokhrel, S., Quigley, M., et al. (2012). Preventing disease and saving resources: the potential contribution of increasing breastfeeding rates in the UK. London: UNICEF UK.

[9] Desclaux A et Taverne B., 2000. Allaitement et VIH en Afrique de l'Ouest: De l'anthropologie à la santé publique. Collection Médecines du monde, Paris, Les Éditions Karthala, $556 \mathrm{pp}$.

[10] Sawadogo PS; Martin-Prével Y; Savy M; Kameli Y; Traissac P. An infant and child feeding index is associated with the nutritional status of 6 - to 23 -month-old children in rural
Burkina Faso. Journal of Nutrition. 2006 Mar; 136 (3):656663.

[11] Chin, A. C., Myers, L., \& Magnus, J. H., 2008. Race, education, and breastfeeding initiation in Louisiana. Journal of Human Lactation, 24, 175-185.

[12] Chalmers, B, Levitt C, Heaman M, O'Brien B, Suave R \& Kaczorowski J., 2009. For the Maternity Experiences Study Group of the Canadian Surveillance System. Breastfeeding rates and hospital breastfeeding practices in Canada: A national survey of women. Birth, 36, 122-132

[13] Oakley LL, Renfrew MJ, Kurinczuk JJ, et al., 2013. Factors associated with breastfeeding in England: an analysis by primary care trust. BMJ Open, 3: e002765.

[14] Karimi B, Sani MZ, Ghorbani R, Danai N. The Pregnant Mothers' Knowledge about Breastfeeding in Semnan, Iran. Middle East J Rehabil Health. 2014 July; 1 (1): e20833.

[15] Jones G, Steketee RW, Black RE, Bhutta ZA and al., 2003. Child Survival Study Group. How many child deaths can we prevent this year? Lancet, 362:65-7.

[16] Institut National de la Statistique et de la Démographie (INSD) et ICF International, 2012. Enquête Démographique et de Santé et à Indicateurs Multiples du Burkina Faso 2010. Calverton, Maryland, USA: INSD et ICF International.

[17] Ruel MT, Menon P., 2002. Child feeding practices are associated with child nutritional status in Latin America: innovative uses of the demographic and health surveys. J Nutr, $132(6): 1180-7$.

[18] WHO/UNICEF. Global Strategy on Infant and Young Child Feeding [Internet]. Geneva, World Health Organization 2003. Available from http://apps.who.int/iris/bitstream/handle/10665/42590/924156 2218.pdf.

[19] Inoue M, Binns CW, Otsuka K, Jimba M and Matsubara M., 2012. Infant feeding practices and breastfeeding duration in Japan: A review. International Breastfeeding Journal, 7:15.

[20] Siri Baperman AA, Bengaly Marcel, Garanet Franck, Kouanda Zeynab, Coulibaly Soumaila, Catraye D Joseph, Sorgho Evrard. Knowledge, Opinions and Attitudes of Mothers About Breastfeeding and Child Feeding in Rural Areas of Burkina Faso: A Study in Ouargaye's District Health Facilities. Journal of Family Medicine and Health Care. Vol. 4, No. 3, 2018, pp. 13-19.

[21] Lee AC, Katz J, Blencowe H, Cousens S, Kozuki N, Vogel JP, et al.; CHERG SGA-Preterm Birth Working Group. National and regional estimates of term and preterm babies born small for gestational age in 138 low-income and middle-income countries in 2010. Lancet Glob Health. 2013 Jul; 1 (1): e2636. http://dx.doi.org/10.1016/S2214-109X (13)70006-8 pmid: $25,103,583$.

[22] Maureen O'Leary a, Karen Edmond b, Sian Floyd a, Sam Newton c, Gyan Thomas d \& Sara L Thomas. A cohort study of low birth weight and health outcomes in the first year of life, Ghana. Bulletin of the World Health Organization 2017; 95:574-583. doi: http://dx.doi.org/10.2471/BLT.16.180273.

[23] Barker DJ. The developmental origins of adult disease. J Am Coll Nutr. 2004; 23:588S95S. 
[24] Maïga EWH. The Impact of Mother's Education on Child Health and Nutrition in Developing Countries: Evidence from a Natural Experiment in Burkina Faso. African Center for Economic Transformation. Accra, Ghana; 2011. Report No.: I15, I25, I28.

[25] Makoka. Donald. The Impact of Maternal Education on Child Nutrition: Evidence from Malawi, Tanzania, and Zimbabwe. DHS working papers. February 2013 No. 84. ICF International Calverton, Maryland, USA

[26] Olusanya, B. O.; Wirz, S. L.; Renner, J. K. Prevalence, pattern and risk factors for undernutrition in early infancy using the WHO Multicentre Growth Reference: A community-based study. Paediatr. Périnat. Epidemiol. 2010, 24, 572-583.

[27] Fishman SM, Caul fi eld L, de Onis M, et al. Childhood and maternal underweight. In: Ezzati M, Lopez AD, Rodgers A, Murray CLJ, eds. Comparative quantification of health risks: global and regional burden of disease attributable to selected major risk factors. Geneva: World Health Organization, 2004: 39-161.

[28] Akombi, B. J.; Agho, K. E.; Hall, J. J.; Merom, D.; AstellBurt, T.; Renzaho, A. M. Stunting and severe stunting among children under-5 years in Nigeria: A multilevel analysis. BMC Pediatr. 2017, 17, 15.
[29] Yisak, H.; Gobena, T.; Mesfin, F. Prevalence and risk factors for under nutrition among children under five at Haramaya district, Eastern Ethiopia. BMC Pediatr. 2015, 15, 212.

[30] Chirande, L.; Charwe, D.; Mbwana, H.; Victor, R.; Kimboka, S.; Issaka, A. I.; Agho, K. E. Determinants of stunting and severe stunting among under-fives in Tanzania: Evidence from the 2010 cross-sectional household survey. BMC Pediatr. 2015, 15, 165. [CrossRef] [PubMed]

[31] Black RE, Allen LH, Bhutta ZA, Caulfield LE, de Onis M, Ezzati M, Mathers C, Rivera J: Maternal and child undernutrition: global and regional exposures and health consequences. Lancet 2008, 371:243-260.

[32] Bork K, Cames C, Barigou Sabah, Cournil Amandine, and Diallo Aldiouma., 2012. A Summary Index of Feeding Practices Is Positively Associated with Height-for-Age, but Only Marginally with Linear Growth, in Rural Senegalese Infants and Toddlers. The Journal of Nutrition [25 Apr 2012, 142 (6):1116-1122].

[33] Zhang J, Shi L, Wang J, Wang Y. An infant and child feeding index is associated with child nutritional status in rural China. Early Hum Dev. 2009Apr; 85 (4):247-52. 